Check for updates

Cite this: RSC Adv., 2018, 8, 22331

Received 18th April 2018

Accepted 24th May 2018

DOI: $10.1039 / \mathrm{c} 8 \mathrm{ra03308k}$

rsc.li/rsc-advances

\section{Amberlite-15 promoted an unprecedented aza Michael rearrangement for one pot synthesis of dihydroquinazolinone compounds $\uparrow$}

\author{
V. Narayana Murthy, ${ }^{\text {ab }}$ Satish P. Nikumbh, ${ }^{a}$ Krishnaji Tadiparthi, ${ }^{c}$ M. V. Madhubabu, ${ }^{a}$ \\ Subba Rao Jammula, ${ }^{a}$ L. Vaikunta Rao*b and Akula Raghunadh (iD *a
}

A new one pot multicomponent annulation strategy for the synthesis of various dihydroquinazolinone compounds has been developed using Amberlite-15 as a catalyst, giving good to moderate yields. In this reaction the substrate scope for amines and aldehydes was also investigated. The reaction has been checked on a large scale and the possible reaction mechanism has also been proposed.
Functionalized dihydroquinazolinone frameworks are present in many biologically active molecules like quinethazone (A), fenquizone (D), benzouracil (B), evodiamine (C), NC1 substance1D19143 (E) and proquazone (F) (Fig. 1). Among the various dihydroquinazolinone compounds, some of them show various potential therapeutic effects, such as antidiabetic, ${ }^{1}$ anticancer, ${ }^{2}$ antihypertension, ${ }^{3}$ anticonvulsant, ${ }^{4}$ antibacterial, ${ }^{5}$ anti-inflammatory, ${ }^{6}$ and antianxietic activities. ${ }^{7}$ Moreover these compounds have also been used as antihistamine, antidepressant and vasodilating agents. Owing to their application in the medicinal and agro industries, ${ }^{8,9}$ many researchers around the world have put substantial efforts into the preparation of these compounds by various synthetic approaches.
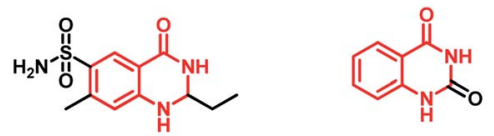

Quinethazone (A)<smiles>Cc1cc2c(cc1S(N)(=O)=O)C(=O)NC(c1ccccc1)N2</smiles>

Fenquizone (D)

$$
\text { Benzouracil (B) }
$$

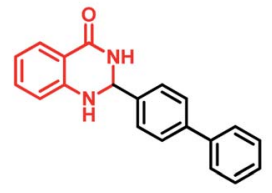

NC1 Substance 1D19143 (E) (Anticancer)

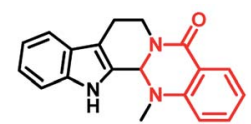

Evodiamine (C)

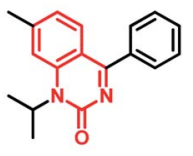

Proquazone (F)
Fig. 1 Few examples of natural and biologically active molecules with dihydroquinazolinone unit.

${ }^{a}$ Technology Development Centre, Custom Pharmaceutical Services, Dr Reddy's Laboratories Ltd, Hyderabad 500049, India. E-mail: raghunadha@drreddys.com ${ }^{b}$ Department of Chemistry, GIS, Gitam University, Visakhapatnam 530045, India 'Department of Chemistry, Christ University, Hosur road, Bangalore 560029, India $\dagger$ Electronic supplementary information (ESI) available. See DOI: $10.1039 / \mathrm{c} 8 \mathrm{ra} 03308 \mathrm{k}$
Indeed from the last few years various synthetic methods have been reported for the construction of various dihydroquinazolinones derivatives (Scheme 1). ${ }^{10,11}$ Bunce et al. reported the synthesis of substituted quinazolinones using a dissolving metal reduction-condensative cyclization strategy, ${ }^{12} \mathrm{Pal}$ et al. synthesized 6,6a-dihydroisoindolo[2,1-a] quinazoline-5,11-dione derivatives by employing a three component reaction of isatoic anhydride, an amine and 2formyl benzoic acid, using montmorillonite $\mathrm{K} 10$ as the catalyst, ${ }^{13}$ and the Sashidhara team also reported the synthesis of dihydroisoindolo[2,1- $a]$ quinazoline-5,11-dione by using acetic acid. ${ }^{14}$ However among all the methods, the investigation of a practical and efficient multicomponent reaction for the synthesis of isoquinoline units with different nucleophiles has

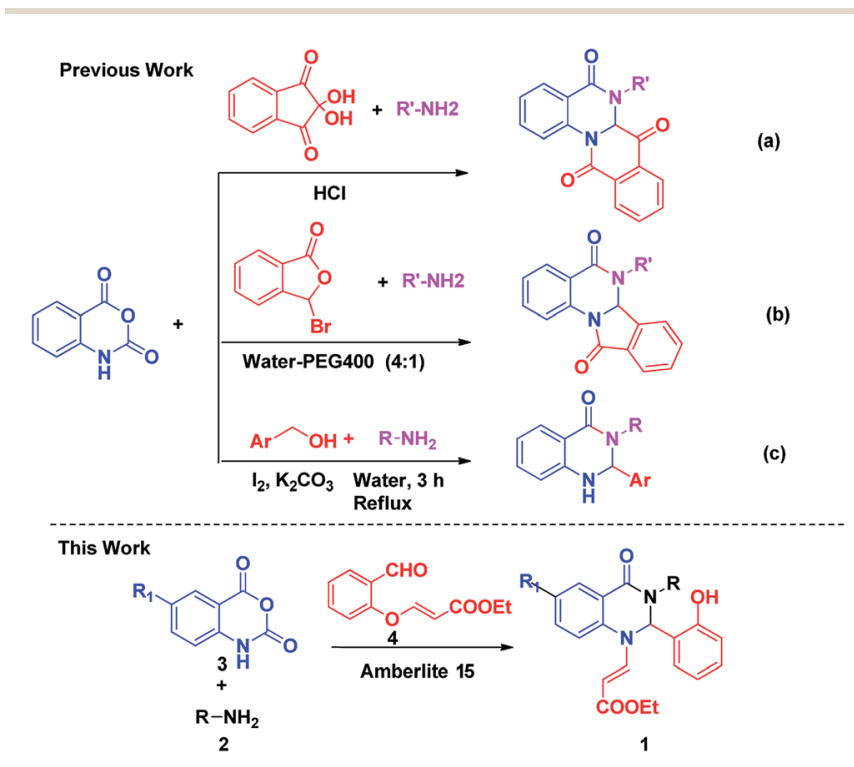

Scheme 1 Various pathways for the construction of different dihydroquinazolinones moieties from isatoic anhydride. 
Table 1 Screening of solvents using Amberlite-15 as catalyst

\begin{tabular}{lll}
\hline S. no. & Solvent & Isolated yield (\%) \\
\hline 1 & DMSO & 28 \\
2 & DMF & 30 \\
3 & 1,4-Dioxane & 64 \\
4 & Methanol & Trace \\
5 & Ethanol & Trace \\
6 & THF & 48 \\
7 & Toluene & 40 \\
8 & Acetonitrile & 53
\end{tabular}

attracted many researchers because of their broad functional groups and simple construction of molecular architectures. Our group previously reported numerous protocols for the synthesis of quinazolinone based biologically active natural products and their derivatives. In continuation of our earlier efforts ${ }^{15}$ for the development of novel synthetic methods, herein we would like to report a new elegant one pot strategy for the construction of novel functionalized dihydroquinazolinones by the condensation of isatoic anhydride, amine and aldehyde.

We commenced our investigation with the model substrate by taking isatoic anhydride (3), butyl amine and aldehyde (4) as depicted in Table 1. In the first step of optimization, the reaction was screened with various catalysts like Wang resin, glacial acetic acid, $\mathrm{BF}_{3} \cdot \mathrm{OEt}_{2}, \mathrm{TiCl}_{4}, \mathrm{FeCl}_{3}$ and Amberlite- 15 in the presence of 1,4-dioxane as a solvent. Gratifyingly by using Amberlite-15 as a catalyst, we found a new functionalized dihydroquinazolinones compound. But using the other acid catalysts, the product with one double bond compound $\mathbf{1 3}$ was obtained as depicted in Fig. 2 along with the product 1 . To optimize the molar ratio of the Amberlite- 15 catalyst, initially we screened the reaction with 0.05 (w/w\%) of Amberlite- 15 and reaction was completed within $7-8 \mathrm{~h}$ and whereas with $0.10 \mathrm{(w} /$ $\mathrm{w} \%)$ of the catalyst, the reaction was completed within 3-4 h. In the next stage, the reaction was investigated in different solvents like DMSO, DMF, 1,4-dioxane, ethanol, methanol, THF, toluene and acetonitrile. Among all the solvents, the reaction was not progressed well with polar protic solvents like ethanol and methanol, whereas in polar aprotic solvents DMSO and DMF nearly $30 \%$ of the product formation was observed. Finally, we found that the reaction providing promising yields in 1,4-dioxane as solvent (Table 1). Indeed, the reaction rate is slow at room temperature and is fast under reflux conditions.<smiles>[R]n1c(-c2ccccc2O/C=C/C(C)=O)nc2ccccc2c1=O</smiles>

Fig. 2 The product with other acid catalysts.
Further the reaction was also checked in 10 and $20 \mathrm{vol}$ but there is no difference in terms of yield and purity. The aza Michael addition step was attempted with 1 eq. of TBAF but only $15 \%$ of the product was observed whereas with 2 equivalent of TBAF, $60 \%$ of the product was observed whereas with 3 equivalent of TBAF the reaction was completed.

After optimizing the reaction conditions, we extended our studies for substrate scope of amines, aldehydes with isatoic anhydride and bromoisatoic anhydride. The substrate scope with various aliphatic, cyclic and aryl amines were studied and to our delight there is no abnormality in terms of yield and purity. This clearly states that all the substrates are well tolerated under these conditions to get the reasonable good yields (Table 2). Furthermore in order to elaborate the synthetic utility of this methodology we have extended our studies by performing a reaction on gram scale (Scheme 2) and gratefully we could replicate the yield and purity which clearly indicating that the reaction can be carried out on large scale.

In order to gain insight into the mechanism, few control experiments have also been carried out. In the first experiment, the reaction with isatoic anhydride and amine without the aldehyde was carried out which provided the ring opening of the anhydride to get the anthranilide. In the second experiment, aldehyde with amine was carried out and the corresponding imine was obtained. In the third experiment, isatoic anhydride

Table 2 Synthesis of various dihydroquinazolinones derivatives ${ }^{a}$

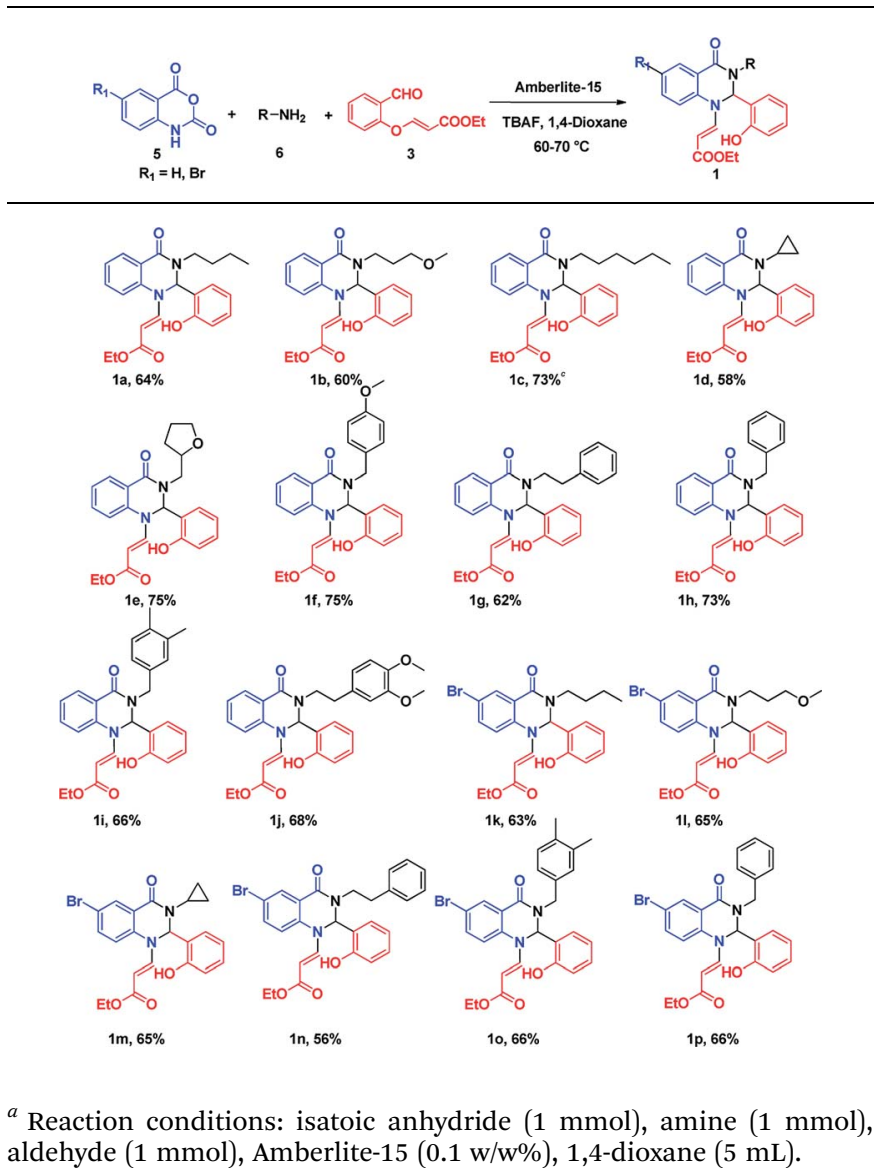




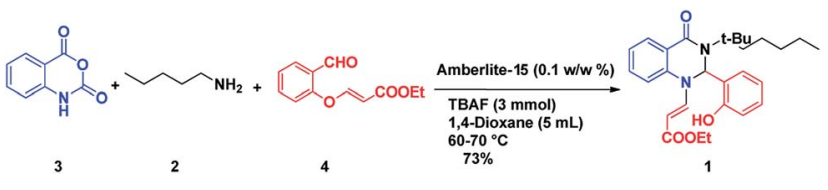

Scheme 2 Gram scale experiment.

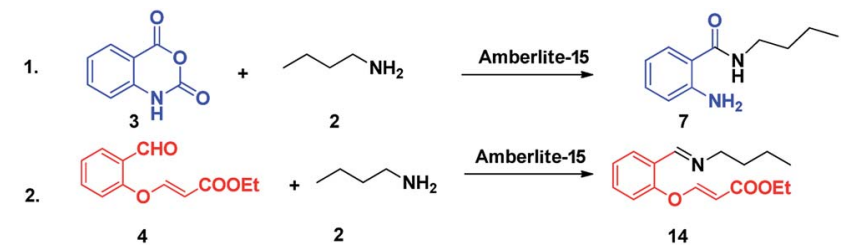

Scheme 3 Control experiments.

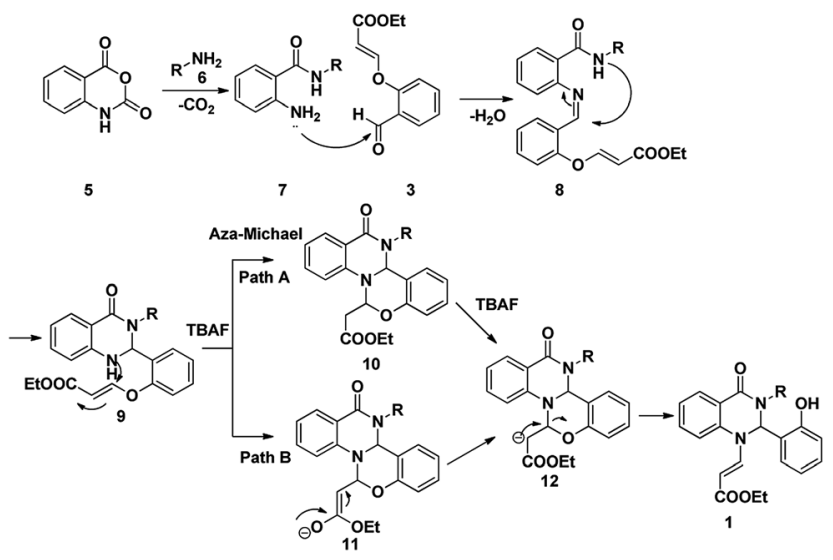

Scheme 4 Plausible mechanism for the formation of dihydroquinazolinones

with aldehyde was carried out in the presence of the catalyst but the starting materials were intact (Scheme 3).

From the above experimental data and literature reports, we have postulated a new possible reaction mechanism (Scheme

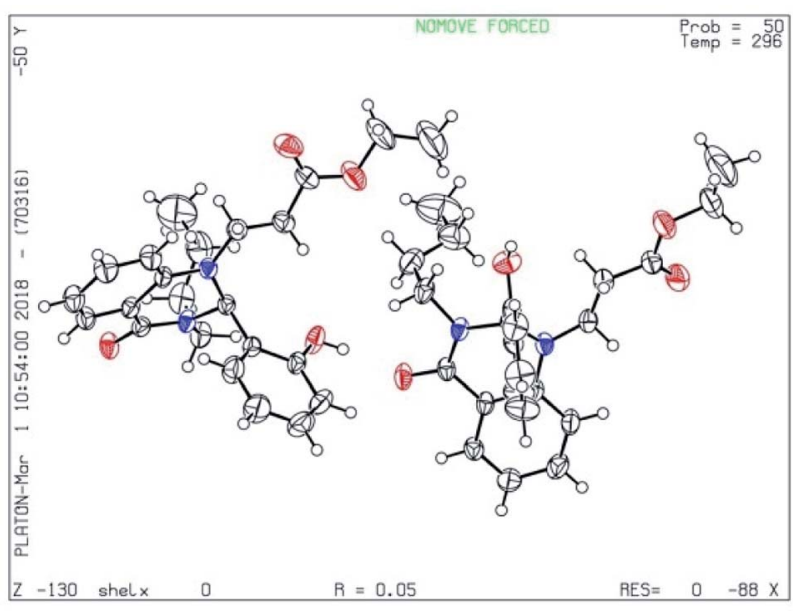

Fig. 3 X-ray crystal structure of 1a (ORTEP diagram).
4). In addition to the spectroscopic evidence, the chemical structure of dihydroquinazolinone $\mathbf{1}$ was further confirmed from the single crystal X-ray diffraction analysis (Fig. 3).

The Scheme 4 describes a plausible mechanism for the three component reaction leading to the compound $\mathbf{1}$. The nucleophilic attack of primary amine on carbonyl group of isatoic anhydride followed by ring opening and subsequent decarboxylation will yield to compound 7 . Nucleophilic attack of amine to the aldehyde will yield imine intermediate 8 ; which on subsequent cyclization lead to the formation of $\mathbf{9}$. Nucleophilic attack of amine on the double bond via aza Michael reaction will yield the tetracyclic intermediate $\mathbf{1 0}$ or $\mathbf{1 1}$ which on further rearrangement leads to the formation of dihydroquinazolinones 1 .

\section{Conclusion}

In summary we have demonstrated the synthesis of novel functionalized dihydroquinazolinones using Amberlite-15 as a catalyst. It is a one pot multicomponent annulation strategy with broad substrate scope and the products obtained were in moderate to good yield. Moreover, the reaction is atom economic, metal-free and mild reaction conditions. Furthermore, these reactions are scalable and simple workup procedures. Further investigation of these types of model substrates is underway in our laboratory.

\section{Conflicts of interest}

We confirm that this manuscript has not been published elsewhere and is not under consideration by any other journal. All of the authors agreed with submission to RSC Advance. We have no conflicts of interest to declare.

\section{Acknowledgements}

The authors would like to thank Dr Rama Mohan, Dr Reddy's Laboratories for the support to carry out this work and Dr Shubu M. Eappen, Kochi University, Kerala for single crystal data.

\section{References}

1 M. S. Malamas and J. Millen, J. Med. Chem., 1991, 34, 1492.

2 (a) J. B. Jiang, D. Hesson, B. Dusak, D. Dexter, G. Kang and E. Hamel, J. Med. Chem., 1990, 33, 1721; (b) S. L. Cao, Y. P. Feng, Y. Y. Jiang, S. Y. Liu, G. Y. Ding and R. T. Li, Bioorg. Med. Chem. Lett., 2005, 15, 1915.

3 J. W. Chern, P. L. Tao, K. C. Wang, A. Gutcait, S. W. Liu, M. H. Yen, S. L. Chien and J. K. Rong, J. Med. Chem., 1998, 41, 3128.

4 J. F. Wolfe, T. L. Rathman, M. C. Sleevi, J. A. Campbell and T. D. Greenwood, J. Med. Chem., 1990, 33, 161.

5 (a) W. Pendergast, J. V. Johnson, S. H. Dickerson, I. K. Dev, D. S. Duch, R. Ferone, W. R. Hall, J. Humphreys, J. M. Kelly and D. C. Wilson, J. Med. Chem., 1993, 36, 227; (b) P. P. Kung, M. D. Casper, M. D. Cook, L. L. Wilson, 
L. M. Risen, T. A. Vickers, R. Ranken, L. B. Blyn, J. R. Wyatt and P. D. Cook, J. Med. Chem., 1999, 42, 4705.

6 (a) F. Rorsch, E. Buscato, K. Deckmann, G. Schneider, M. S. Zsilavecz, G. Geisslinger, E. Proschak and S. Grosch, J. Med. Chem., 2012, 55, 3792; (b) S. E. De Laszlo, C. S. Quagliato, W. J. Greenlee, A. A. Patchett, R. S. L. Chang, V. J. Lotti, T. B. Chen, S. A. Scheck and K. A. Faust, J. Med. Chem., 1993, 36, 3207.

7 C. Mustazza, A. Borioni, I. Sestili, M. Sbraccia, A. Rodomonte, R. Ferretti and M. R. D. Giudice, Chem. Pharm. Bull., 2006, 54, 611.

8 (a) Comprehensive Heterocyclic Chemistry III, ed. A. R. Katritzky, C. A. Ramsden, E. F. V. Scriven and R. J. K. Taylor, Elsevier, Oxford, UK, 2008; (b) D. A. Horton, G. T. Bourne and M. L. Smyth, Chem. Rev., 2003, 103, 893.

9 (a) S. B. Mhaske and N. P. Argade, Tetrahedron, 2006, 62, 9787; (b) S. H. Lee, J.-K. Son, B. S. Jeong, T.-C. Jeong, H. W. Chang, E.-S. Lee and Y. Jahng, Molecules, 2008, 13, 272. 10 (a) C. Jagan mohan Reddy, K. P. V. Kumar, G. S. Reddy, S. Mohanty, J. Kumar, B. V. Rao, T. Krishnaji and A. Raghunadh, Synth. Commun., 2018, 48, 168-174; (b) V. N. Murthy, S. P. Nikumbh, S. P. Kumar, Y. Chiranjeevi, L. V. Rao and A. Raghunadh, Synlett, 2016, 27, 2362; (c) S. B. Azimi and J. Azizian, Tetrahedron Lett., 2016, 57, 181; (d) J. Zhang, J. Zhao, L. Wang, J. Liu, D. Ren and Y. Ma, Tetrahedron, 2016, 72, 936; (e) S. B. Azimi and J. Azizian, Synlett, 2016, 27, 1836; (f) T. Fatemeh, K. Varnamkhasti and M. Taghi, Synlett, 2016, 27, 2510; $(g)$ M. V. M. babu, R. Shankar, G. R. Reddy, T. S. Rao, M. V. B. Rao and A. Raghunadh, Tetrahedron Lett., 2016, 57, 5033; (h) J. Yang, S. Sun, B. Zhang, J. Zhang and Y. Gu, Tetrahedron, 2014, 70, 9214-9223; (i) S. Sun, C. Cheng, J. Yang, A. Taheri, D. Jiang, B. Zhang and Y. Gu, Org. Lett., 2014, 16, 4520-4523; (j) M. Mahdavi, N. Foroughi, M. Saeedi, M. Karimi, H. Alinezhad, A. Foroumadi, A. Shafiee and
T. Akbarzadeh, Synlett, 2014, 25, 385-388; (k) T. Kalai, B. Bognar, D. Zsolnai, Z. Berente and K. Hideg, Synthesis, 2012, 44, 3655-3660.

11 (a) P. V. N. S. Murthy and D. Rambabu, Tetrahedron Lett., 2012, 53, 863; (b) S. Kiaee, A. Masoumnia and M. Maghsoodlou, Res. Pharm. Sci., 2012, 7; (c) J. Chen, D. Wu, F. He, M. Liu, H. Wu, J. Ding and W. Su, Tetrahedron Lett., 2008, 49, 3814; (d) J. X. Chen, W. K. Su, H. Y. Wu, M. C. Liu and C. Jin, Green Chem., 2007, 9, 972; (e) M. Rueping, A. P. Antonchick, E. Sugiono and K. Grenader, Angew. Chem., Int. Ed., 2009, 48, 908; (f) R. J. Abdel-Jalil, W. Voelter and M. Saeed, Tetrahedron Lett., 2004, 45, 3475; (g) Z. Jianguang and F. Jie, J. Org. Chem., 2011, 142, 631; (h) X. Cheng, S. K. Vellalath, R. Goddard and B. List, J. Am. Chem. Soc., 2008, 130, 15786.

12 R. A. Bunce and B. Nammalwar, J. Heterocycl. Chem., 2011, 48, 991.

13 K. S. Kumar, P. M. Kumar, M. A. Reddy, M. Ferozuddin, M. Sreenivasulu, A. A. Jafar, G. R. Krishna, C. M. Reddy, D. Rambabu, K. Shiva Kumar, S. Pal and M. Pal, Chem. Commun., 2011, 47, 10263-10265.

14 K. V. Sashidhara, G. R. Palnati, S. R. Avula and A. Kumar, Synlett, 2012, 23, 611.

15 (a) M. V. Madhubabu, R. Shankar, S. M. Satish, M. V. Basaveswara Rao, U. K. Syam Kumar and A. Raghunadh, RSC Adv., 2016, 6, 36599; (b) R. K. Raghavendra, M. Ramamohan, A. Raghunadh, B. M. Suresh, K. S. Praveen, D. Kalita, E. Laxminarayana, B. Prasad and M. Pal, $R S C A d v$., 2015, 5, 61575; (c) A. V. D. Rao, B. P. Vykunteswara rao, K. T. Bhaskar, R. J. Nivrutti, K. Dipak, J. D. L. Kumar, V. Siddaiah, S. P. Douglas and A. Raghunadh, Tetrahedron Lett., 2015, 56, 4714; (d) N. V. Murthy, S. P. Nikumbh, S. Praveen Kumar, L. Vaikunta Rao and A. Raghunadh, Tetrahedron Lett., 2015, 56, 5767. 